\title{
A Survey of the Present Situation and Problem Analysis of College English Writing-From the Perspective of Passive Voice
}

\author{
Li Fengjie, Tao Ran, Wang Chaoyang \\ Foreign Languages Department, School of Humanities, Tianjin University of Finance and Economics, Tianjin, China
}

Email address:

Yyfx0901@163.com (Li Fengjie)

\section{To cite this article:}

Li Fengjie, Tao Ran, Wang Chaoyang. A Survey of the Present Situation and Problem Analysis of College English Writing-From the Perspective of Passive Voice. International Journal of Literature and Arts. Vol. 5, No. 5, 2017, pp. 52-59. doi: 10.11648/j.ijla.20170505.12

Received: May 16, 2017; Accepted: May 22, 2017; Published: September 7, 2017

\begin{abstract}
Passive voice is one of the most important and difficult grammatical items both in English and in Chinese. Because of the great differences between passive voices in English and in Chinese, Chinese EFL (English as a foreign language) learners undoubtedly run into a lot of difficulties during the time of learning English passive voice. Different from the previous research, this thesis is a corpus-based study focusing on passive errors made by Chinese EFL learners, especially under-used passive errors, over-used passive errors and malformed passive errors. Based on the three important theories in language acquisition: contrastive analysis, interlanguage analysis and error analysis, this thesis will analyze the data acquired from the corpus set up from one of the classes in one university in China. And the major reasons for these errors will be revealed in this research. The findings in this thesis are hoped to have some influence on English passive teaching.
\end{abstract}

Keywords: Corpus, Error Analysis, Contrastive Analysis, Interlanguage Analysis, Passive Voice

\section{Introduction}

After studying English for at least thirteen years, the authors find that passive voice is one of the most typical and vital grammar items in English language as it can distinguish the more important elements in the sentences and can express information more decently and properly. However, people in western countries and China pay different degree of attention to using passive voice. What's more, due to different habits of using passive voice, there are a lot of errors made by Chinese EFL learners which can be seen obviously in their writings. In order to improve the teaching level of Chinese EFL learners, a large number of researchers have already stepped into this field and conducted relevant studies to find solutions to the passive voice errors.

Students' cognitive competence and ability of self-discipline are driven to maturity stage during their studies in university. Thus, it is a prime stage for both teachers and students to make a joint effort to improve the level of English learning. Standing on the shoulder of predecessors, the authors will analyze the corpus that are composed of writings collected from English majors of one university in China. With the aim of making contributions to the teaching of the passive voice in English, two questions are proposed.

1) Does the time span of English learning pose influence on the performance of passive voice acquisition?

2) What are the respective features of the three types of errors?

By analyzing the passages in the corpus, which the authors collected from the writings in one class for a term, this thesis manages to recognize the errors of passive voice and classify those errors into different groups, following the illustrations of them. From where both teachers and students stand, some suggestions will be presented in this thesis.

\section{Literature Review}

In this part, the error analysis, contrastive analysis and interlanguage analysis will be introduced to draw a whole picture of the theoretical framework. As three main pillar theories in applied linguistics, with the development of study procedure, the author finds that we can not split any of them. That is, these three theories are interdependent and 
supplement each other.

\subsection{Error Analysis and Contrastive Interlanguage Analysis}

In this part, the definitions, characteristics of error analysis and contrastive interlanguage analysis will be presented as follows.

\subsubsection{Error Analysis}

Errors are the performance of using this new language to digress from some existing regulations and are unsuccessful bits of language. They are inevitable and common. However, if EFL learners don't pay attention to the errors they made, misunderstanding would happen, and the informative function of language may lose efficacy. Thus error analysis rise in response to the proper time and conditions. According to the previous research, the author finds that error analysis is the development of contrastive analysis and plays its role on the basis of interlanguage theory. It provides researchers a methodology for the investigation and description of EFL learners' learning performance. Through Error Analysis, researchers can make a bilingual comparison, by which the EFL learners' interlanguage and the target language will be compared.

In order to make sure the accuracy of the results of researches, it is vital to make a distinction between mistakes and errors, which are two different phenomena in linguistics. "An error is a noticeable deviation from the grammar of the native speaker, reflecting the inter-language competence of the learner." (Brown, 2006: 75). If someone commits errors, it means a lack of competence. However, the mistake can be made by anyone. As the phenomenon of the slip of the tongue is very common and understandable. That is, the native speaker or the EFL can have a bad performance when they speak due to the language processing problems and communication strategies. For instance, both the native speakers and EFL learners may misname an acquaintance, or can omit "be" because of being nervous and can revise that immediately.

\subsubsection{Concept and Features of the Interlanguage}

Interlanguage is a language variety stemming from the process of learning a new language. It is created by language learners and work as a transition and intermediate state between mother tongue and target language. Interlanguge is much more like a path delving into the deep place in EFL learners' mental world, through which the EFL researcher can figure out the way EFL learners construct the target language. And it is also like a progress bar of the development of learning the target language. Thus, interlanguage renders academia an approach to find the wrong usage of grammar and words of the target language and revised method will become available.

After the overview of the previous related researches, three traits of interlanguage can be summarized as follows: First of all, interlanguage is permeated due to the amendable regulation that comprises the EFL learners' background of language. Second, it is dynamic. Because EFL learners input new and correct information continuously, the knowledge structure will be updated and errors which appear in learners' interlanguage will decline greatly. Finally, interlanguage is systematic. As EFL learners' errors are systematic and regular, which can be found after analyzing EFL learners' writings. It is possible to realize that the rule-based nature of the learners' learning of their foreign-language may cause a systematical interlanguage.

\subsection{Contrastive Analysis of Passive Voice}

\subsubsection{Contrastive Analysis}

Contrastive Analysis is also called Contrastive Linguistics. In this analysis, the researcher will compare and contrast the target language and the mother tongue simultaneously in order to figure out and generalize the similarities and differences of these two systems. And then the achievements can be applied to related fields of research. Eventually, the teaching material as well as teaching efficiency can be refined.

Contrastive Linguistics of English and Chinese makes a prominent contribution to the globalization and intercultural communication, because English and Chinese are the two giant languages that possess the most users. The next section will focus on the Contrastive Analysis of English and Chinese passive voice. At first, it is primary for researchers to understand what voice is. Word "voice" stems from latin word "vox". Voice is a format of verbs and reveals the relationship between the subject and the predicate. With different sentence structures or different voices used, the sentence can deliver the same meaning but underline different elements. For example, "Jennifer bought a book" is written in active voice emphasizing the doer "Jennifer". "A book was bought by Jennifer" is written in passive voice highlighting the patient "A book".

\subsubsection{English Passive Construction}

English, as a kind of inflectional language, the verb has the characteristic of morphological changes, thus has a state of the grammatical category. When the agent is in the position of subject, the verb takes the form of active voice. For example, the verb in "My father built the house last year" is active voice. On the other hand, if the recipient is in the place of subject, the verb takes the form of passive voice. For instance, "The house was built by my father last year." That is, the form of verbs is decided by the subject. And the basic form of passive voice is "be + p.p. + by".

According to the diverse cultures in China and English speaking countries, the Chinese fancy animate subjects, while the people in English speaking areas use inanimate subjects universally. And the most typical situations where passive voice is used will be introduced in this part.

1) When we don't know or don't need to know the executor of the action, we use passive construction.

E.g. A metropolitan shopping mall is built in our city.

2) When the recipient of the action need to be emphasized, we use passive construction.

E.g. Mr. Wang was elected chairman of the committee. 
3) When we don't want to mention the doer out of politeness, conversation strategy or euphemism, we use passive voice.

E.g. You will be contacted.

4) Some words accustomed to being used in passive construction.

E.g. He is said to be competent and responsible.

It is hoped that everyone can be treated gently by this society.

Generally, context and language form is related directly. Namely, a certain form of language can only appear in a certain context. According to the predecessors of this kind of research, the typical stylistic features of passive voice, are impersonal, formal, and prepared. Therefore, passive voice appears in the scientific literature and news reports in the high frequency, adapting to the special requirements of such writing style: the expression of objective facts and scenarios, emphasizing the process and results of the application, without subjective color.

Passive construction is so common in English that most active constructions can be transformed into passive constructions. However, due to the constraints in English passive voice, not all the active constructions can be transformed into passive ones. In this part, this thesis will introduce two major types of constraints in English passive voice.

The first type is verb constraint. According to the definition of English passive voice, we can know that the transitive verbs in English can have passive voice, but intransitive verb and copular verb have no passive voice. Whereas, not all transitive verbs have the form of passive voice, there are some transitive verbs in English which can only subject to active voice, which generally represent states rather than actions. Therefore, we can call these verbs "static verb".

E.g. (5) She lacks her confidence.

*Her confidence is lacked by her.

(6) This pair of shoes doesn't fit me.

*I am not fit by this pair of shoes.

(7) Jack resemble his mother.

*Jack's mother is resembled by him.

Transitive verbs that are subject to active construction include "resemble, race, let, suit, survive, get, lack, fit, have, elude, escape, flee" and so on. But words like "born, say, rumor, acclaim" are usually used in passive voice.

The second type is object constraint. When the clause stands in the position of object in active construction, we can not transfer it into passive voice.

E.g. (8) She thought that her son is a perfect singer.

*That her son is a perfect singer is thought by her.

(9) I enjoy doing yoga.

* Doing yoga is enjoyed by me.

Another point is that the grammatical relationship between subject and reflective, reciprocal and possessive pronouns hold back the passive transformation.

E.g. (10) You will hurt yourself if you play with fire.

*Yourself will be hurt if you play with fire.
(11) We supervised each other during our school days. *Each other was supervised by us during our school days.

(12) I waved my hand when I met my friends.

*My hand was waved by me when I met my friends.

\subsubsection{Chinese Passive Construction}

As for English majors, we all know that Chinese is topic-prominent language, which means topic-comment plays a major role in Chinese, and the so called subject position is just with respect to the topic of this sentence instead of the body of making movement. Just as we Chinese always say "language is not words but meanings", we focus on the meanings most of the time. Because Chinese characters are hieroglyphic, we even can understand each other through fragmentary words. For example, when we say "wei, mai shu le ma? (Excuse me, have you bought the book?)", people involved in this conversation can understand each other totally.

On the contrary, English is subject-prominent language. That is, the grammatical relationship between subject and predicate plays a major role in the formation of English sentence. Namely, in English, an agent of a verb occupied the subject position.

What's more, another feature of Chinese stems from the perspective of morphology. Chinese is a typical isolating language whose grammatical functions are displayed by words order and the use of function words with no changes in word forms.

With the overview of modern Chinese, the character "bei" is the typical symbol to indicate the Chinese passive voice. In the standard Chinese passive construction with "bei", the object of the active voice is fronted to the subject position, and the subject-agent is introduced by the passive symbol "bei", following the recipient of the action.

E.g. (13) Laoshi biaoyang le Tony (Our professor praised Tony).

$\sim$ Tony bei laoshi biaoyang le (Tony was praised by our professor).

In the second sentence, "Tony" is the object of the active voice in the first sentence, and fronted to the position of subject. The doer of the action "laoshi" is introduced by "bei".

Despite the character "bei", there are also other characters that can symbolize Chinese passive voice. One group aims to describes the pathetic situation of the person. They are "zao shou, ai" and so on. The other group is composed of "shou yu, gui, gei, rang" is used to depict the neutral or aspiring occasion.

\subsubsection{Active Form with Passive Meaning}

There are some passive sentences both in English and in Chinese, with no passive morphological marker, that is to say, the sentences with active form can express passive meanings.

Firstly, let's move on to the construction of Active Form with Passive Meaning (AFPM) in Chinese. Such syntactically active but semantically passive sentences are pretty common in Chinese and are addressed as the "notional passive". 
E.g. (14) wenzhang xie de henhao (The article was well written)

(15) xin yijing ji le (The letter has been posted)

(16) dianshiji xiuli hao le (The TV set has been repaired).

The sentences mentioned above all share the same feature that the passive marker "bei" is absent and this phenomenon bears a resemblance to English agentless passive construction If we translate those notional passive sentences into English, the agent must be omitted.

E.g. (17) The passage is well written.

(18) The package has been sent.

(19) The fridge has been repaired.

In order to understand the AFPM in English deeply, some specific sentences will be exemplified. Under the following conditions, AFPM in English usually appears.

1) When some verbs work as intransitive verbs, it will make the word in subject position as a patient of this verb.

E.g. (20) Dora's passage reads well.

(21) The accident happened suddenly.

2) To some extent, infinitive can demonstrate passive meaning with active form.

E.g. (22) I have a lot of homework to do.

(23) The mission is difficult to finish.

3) When gerunds are introduced by some special verbs like: "need, want, deserve, bear, require" and so on.

E.g. (24) His writing skill needs improving.

(25) These puppies require looking after carefully.

4) Some intransitive verbs like "owe (qian qian), do (juzhi biaoxian), cook (zuo fan), print (yinshua), build (jianzao) etc.", when they are in their progressive tense, they can express passive meaning.

E.g. (26) The novel is printing.

(27) The plant is building.

AFPM in English is like a freak in English passive construction. In order to master English passive voice, EFL learners are expected to understand and memorize the particular case.

\subsection{Previous Researches on Passive Voice}

In the previous studies "the comparative analysis of the English passive voice and Chinese passive voice" has been explored by the following researchers and scholars: Xie (1999); Xiong \& Wang (2002); Cao (2004); Xie (2004); Tian (2007) and so on. Then comes to the researches about "acquisition of passive voice", it has been probed into by: Wang Yunfeng (2001); Chen Wanxia (2002); Zhuang Hongling (2005); Wang Yuanying (2008); Zhang Jia (2013) and some other researches.

Although many researchers standing on different perspectives and theories devoted their time and energy to the problems in acquisition of English passive voice, inadequate attention has been paid to "errors made by Chinese EFL learners". Only such thesis written by kong Yan (2006); Li Rui (2006); Liu Yao (2007); Ke Linv (2009); Li Tianxin (2009) can be found.

It is crucial to analyze "acquisition of English passive voice" and do a "comparative analysis on the Chinese and
English passive voice"; however, be a further step, if Chinese EFL learners want to improve their performance of using English passive voice, researchers are supposed to use the feedback adequately and effectively, that is, in present research we need to analyze the errors made by English majors of Tianjin University of Finance and Economics. With the assistance of three main theories illustrated above, this thesis will employ corpus-based approach to categorize the errors committed by those students, and reasons and solutions followed closely.

\subsection{Corpus-Based Approach to Language Teaching}

Corpus linguistics refers to the research of language that collectes from samples of authentic situation. Corpus linguistics insists that reliable language analysis is more tenable and feasible with corpora collected from the natural contexts with little subjective interference. The reality of Corpus Linguistics accounts for its prominence in the field of EFL learning and teaching since the mid-1980s. It can be seen from two places. In the first place, it can provide researcher the database of natural utterance and authentic discourse, hence, the study based on it will become more meaningful and objective rather than relying on intuitions and assumptions. In the second place, it enlarges the scope of investigation, which allows researchers to dispose and analyze the subjects sufficiently. Therefore it can provide us with extremely reliable and precise results.

In present thesis, with the help of supervisor $\mathrm{Li}$, the author will mainly focus on the database comprising one hundred and forty-four compositions written by students in Tianjin University of Finance and Economics.

\section{Methodology}

In Chapter Two, the thesis has established the framework of the related theories and given a brief introduction of Corpus Linguistics as well as its implication and application of EFL learning and teaching. The full and accurate theoretical basis lays a solid foundation for the central part of this thesis: gaining through the detailed analysis of the samples and paves the way for working out the solutions of reducing the error frequency of passive voice.

\subsection{Specific Research Questions}

Seeing from the research findings above, it is indispensable to implement a further research on passive voice errors. Thus the original intention of this thesis is to analyze passive errors committed by English majors in Tianjin University of Finance and Economics and summarize the most typical errors. The reasons of these poor performance and solutions will also be interpreted.

Based on the preliminary investigation on the students' writings from our university, the author sets the following as research questions of this thesis.

1) Does the English levels of Chinese college students pose influence on the frequency of using passive voice? 
2) Is there any relationship between the frequency of using passive voice and committing passive voice errors?

The assumption of the researcher can be seen clearly that the author thinks the time span of learning English will influence the performance of EFL learners which are generally related to the quantity of native English inputting, and the English level will have an effect on the frequency of using passive voice, which may affect the frequency of passive errors. In order to check this assumption, the author will carry out following steps.

\subsection{Instruments and Subjects}

In this section, the subjects selected and instruments used in this research will be explained.

\subsubsection{Instruments}

In order to carry out this research smoothly and effectively, with the help from my supervisor, we arranged a task for eighteen college students from Tianjin University of Finance and Economics. In this assignment, those eighteen students with different outputting level of English language were asked to write eight passages on eight fixed topics. All of them were required to write within the range of 100 400 words. Before they uploaded their works, we made sure that they already tried their best to display their authentic state of their English level in terms of grammar, diction, syntax and passage structure in their writings. As the students were chosen randomly in English major, we can pledge the objectivity and accuracy of this research which are the distinctive advantages of corpus-based study.

\subsubsection{Subjects}

There are one hundred and forty-four compositions and more than thirty thousand words in the database. The large number of samples can also give support to the reliability and validity of the final results, which can give contribution to the education of English passive voice.

In the light of the whole picture of the performance of these eighteen college students' writings, the author can generally group them into higher level, middle level and basic level. For example, if a student wrote his or her compositions only in very basic words and expressions, and the word order is more like being translated from Chinese to English; what's more, compared to other students, the number of words is much less than the other students, we can group him or her into basic level. According to similar criteria, the middle level and higher level can also be separated from each other.

\subsection{Procedure of Data Retrieving}

Restricted by the level of expertise and theoretical knowledge, the author carries out the research mainly with the assistance of Microsoft Word. And four major specific steps will be illustrated in the following part.

In Step One, the author will scan the passages from each student to get to know the English level of per student and classify them into corresponding groups which were mentioned above. And the students in the same level will be grouped into one document. What's more the passages written by the same student will also be in one document.

In Step Two, those passages will be read carefully and thoroughly to highlight the sentences written in passive voice. Besides, in this process, it is indispensable to pick out the passive errors committed by those college students and summarize those passive voice errors in a new document. Though, only the raw materials will be dealt with, it set a necessary foundation for the later analysis.

In Step Three, having looked through the passive errors committed by the college students, the author will classify the errors with same features into one group. Thus, eventually, the causes and remedial measures will be found out.

\subsection{Types of the Errors}

After analysis of the datum in the self-made corpus, the author finds that the emergence of these errors lies in the inextricable connection with both interlingual and intralingual factors. According to the morphological characteristics, we can summarize the passive errors into three main types. In this part, three types of errors in passive voice will be interpreted respectively.

\subsubsection{Under-Used Passives}

The under-used passive errors refer to the insufficient passivization of verbs that can be transformed into passive forms. That is, when the fixed collocations which are used to perform in passive voice are written in active voice or the students keep the transitive verbs in active form when the word order is passive construction. Cases related to this error are as follows:

(1) My family moved from Wuhan, where I born.

(2) Of course the picnic basket should bring with you.

(3) So above what we have mentioned, the effects of over development of big cities have many things to consider.

The cases mentioned above are chosen from the self-made corpus concerning under-used passive errors. As "was born" is fixed collocations, thus Case One commits the error of under-used passives. In addition, in Case Two and Three, the transitive verbs "bring" and "consider" are not passivized. Because "picnic basket" and "many things" standing at subject position play the role of recipient of transitive verbs "bring" and "consider".

\subsubsection{Over-Used Passives}

The over-used passive errors refer to the over-extension of passivization, that is non-passivable verbs are passivized.

(4) The teaching buildings are surrounded the lake.

(5) Everyday in the early morning my sweet dream are ended with the terrible noise rising up in the street.

(6) And that's why the popularity of tours to forests and mountains are increased.

(7) Our daily life is also suffered from the noise pollution.

All the sentences mentioned above are ungrammatical passive constructions, as they violate the rules of passivization. In Case Four, "the teaching buildings" are 
the agents of action "surround", and "lake" is the patients of the transitive verb "surround". Therefore, we don't need to use passive voice. It is obvious that the intransitive expressions "end with", "increase" and "suffer from" are not compatible with passive voice in Case Five a Six and Seven.

\subsubsection{Malformed Passives}

When the basic passive structure is not correct totally, we can deem it as malformed passive. Such as an evident omission in structural retrenchment including the lack of the auxiliary "be", the absence of past-participle "-ed"or the obvious addition, which means the emergence of unnecessary words in an ill-formed sentence. Last but not least, malformed passives also includes the wrong form of past-participles.

(8) Of course the picnic basket should also be take into consideration.

(9) Expansion of city need more field which should be use for planting trees or crops.

(10) Next, I was enrolled the Changchun Foreign Language School.

(11) First, because films are focus on the effect, they prefer the atmosphere.

The typical passive constructions are not complete in the cases presented above. In Case Eight and Nine the transitive verbs are not in the form of past-participle. In Case Ten the preposition "by" is absent which makes the utterance faulty. In Case Eleven, we can feel the chaos of writer's writing skills. It seems like that the writer want to use active voice but the "are" should not appear, and if he or she wanted to use passive voice, the positions of "film" and "effect" should be interchanged. And "focus" should be changed into "focused". The students committing this error have the sense of using passive voice, but lack the capacity to use it perfectly.

\section{Results and Discussion}

After analysis in the previous chapter, the results will be revealed and towards the results we will discuss the passive errors in the self-made corpus, and the reasons of these ill-formed passive construction.

\subsection{Passive Errors in the Corpus}

There are two analytical methods -- one is vertical comparison, and the other is horizontal comparison. When the datum gleaned from the same group are compared, we can put it in vertical comparison or intra-group analysis. That datum collected from different categories are compared simultaneously is called horizontal comparison or inter-group analysis. In order to work out better answers to the questions which we raised in the last chapter, we use horizontal comparison mainly.

In the light of the data collected from self-made corpus, the general results of frequency of passive voice errors are shown in the following table.
Table 1. Passive voice errors.

\begin{tabular}{llll}
\hline \multicolumn{2}{l}{ Passive Voice Errors } & & \\
\hline Group & $\begin{array}{l}\text { Under-used } \\
\text { passives }\end{array}$ & $\begin{array}{l}\text { Over-used } \\
\text { passives }\end{array}$ & $\begin{array}{l}\text { Malformed } \\
\text { passives }\end{array}$ \\
\hline Frequency & 4 & 5 & 7 \\
\hline
\end{tabular}

Table 2. Frequency of passive voice errors.

\begin{tabular}{llll}
\hline Passive Voice & & & \\
\hline Group & Higher-level & Middle-level & Basic-level \\
\hline $\begin{array}{l}\text { Frequency of errors } \\
\text { Frequency of Using }\end{array}$ & $7(6.3 \%)$ & $4(8.7 \%)$ & $5(22.7 \%)$ \\
Passive Voice & 111 & 46 & 22 \\
\hline
\end{tabular}

From the tables mentioned above, we can see the frequencies of different types of passive voice errors are different from each other, and the malformed passive occupying the largest proportion. What's more, limited to this research, students in higher-level commit the most errors, and students in middle level make the fewest errors. However, if we take the frequency of using passive voice into consideration, we are surprised to find that the error rates look more reasonable, as the performance of learning target language should benefit from the proficiency of the mastering target language. With the analysis of this results in next part, we will delve into the further findings.

\subsection{Results of the Analysis}

As we can see from the results summarized by analyzing the raw datum from self-made corpus, we can draw following conclusions.

(1) The English level of Chinese college students do pose influence on the frequency of using passive voice.

(2) There are relationships between the frequency of using passive voice and committing passive voice errors.

As students in higher level have already input relatively more materials of target language, which will help them foster a right notion of using passive voice. And their integral level of target language will become more stable, which causes the high frequency of using passive voice but low error rate. With regard to the students in middle level, they are just aware the features of passive voice in target language. Nevertheless, due to the unversed knowledge of English passive voice, the more passives they use, the more errors are committed. After the errors are corrected, they will be better at passive voice. Concerning students in basic level, they show the tendency of translating Chinese into English directly and literally. It is well known that, animate subject is more common for Chinese language thus, English sentences translated from Chinese are always active voice.

\subsection{Causes of the Passive Errors}

Based on the interlingual factors, intralingual factors and induced factors, the data gleaned from self-made corpus have been observed and analyzed by the author, and we can come to a conclusion that Language transfer plays a vital role in the reasons of the under-used passives errors, especially for those 
who are in their low proficiency. And insufficient knowledge of the diverse usages of verbs.

As for over-used errors of passives, after learning English for a period of time, Chinese college students become familiar with the passive voice; however, due to the over-generalization of English passive voice it is common for them to misplace the English passive voice and commit over-used passives errors. What's more it is extremely difficult for Chinese college students to have a good command of rule restriction and lexical constraint, thus the teachers' help is needed in this period.

Lastly, due to the carelessness from students, induced factors among interlingual and intralingual as well as uncertain memory of the past participle form of transitive verbs can also contribute to the malformed passive errors.

\section{Conclusion}

Based on the theoretical underpinning illustrated before, this thesis has already conducted a study on passive errors made by Chinese college students in their writings. In this chapter, the author will present the summary of the findings, pedagogical implications of the research and the limitations of the study.

\subsection{Major Findings of the Research}

On account of the analysis of the three error types of English passive voice, we can eventually draw a conclusion as follows.

At first sight, students commit under-used passive voice error unconsciously, due to their less competence of the double-featured verbs which possess both transitive and intransitive verb features. Additionally, because of under-passivization of the semi-passive structure, the frequency of passive voice error has enhanced. Thus, this ill form of passive construction is mainly ascribed to the incomplete knowledge of English verbs and the negative transfer of the mother tongue.

For a second, over-used passive error usually appears in well-formed active constructions and in unaccusative structures. In addition, some non-passive expressions are passivized unnecessarily and wrongly. Hence, the main reasons for over-used passive error is the insufficient knowledge towards the rules of two voice transformation and the constrains concerning passive construction.

In the final analysis, the possible cause of malformed passive construction made by Chinese college students is the different morphological features of the mother tongue and English. Although this type of error is low content of knowledge, we still need to pay attention to it, because it is really hard for students to shun malformed passive construction.

From the perspective of interlanguage, these findings have already verified that under-generation, over-generation and omission are the typical features of the specific processes to target language in language acquisition.

\subsection{Pedagogical Implications of the Research}

Because the great complexity and confusion of the English passive voice, in order to have a skillful command of it, students are expected to set a solid foundation of passive rules, and figure out the differences between English and Chinese. Besides, students should enlarge the amount of the target language inputting to form a language environment.

As for teachers, they should instruct the rules of passive voice more meticulously, and highlight the major differences between English and Chinese to students. What's more, in order to make sure students understand the rules and exceptions, teachers are supposed to offer some examples and clarify their usages. Once the understanding of passive voice can be incisive and intensified, the performance of students learning passive voice can be improved.

Moreover, the adoption of the Corpus approach provides jumbo convenience and reliability to analysis of the second language acquisition. Researchers can observe the state of second language learners directly and draw a practical conclusion. It is of great significance to use Corpus approach more broadly among linguistics to identify learners' errors and find the respective solutions.

\subsection{Limitations of the Research}

Although the author has already tried her best to conduct the research, due to some objective factors and the author's experience on this subject, there are still some limitations in this research.

On the one hand, the data gleaned from self-made corpus only provide the researcher with limited number of passages, namely the samples are not big enough to get more accurate result. Moreover, the present research didn't take into account the complex nature of learners, including age, IQ, learning style, motivation, aptitude, and social variables as well as the processes of English, which requires a large-scale investigation and high-end analytical methods. Due to some objective factors, it becomes a new subject for future researchers.

On the other hand, all the passive errors sorted from self-made corpus are grouped manually into three types, which may not cover all the cases of the passive voice errors. Thus the accuracy and authority of the present study need to be remedied.

Except for the limitations, the research sheds light on the procedures of teaching and learning of passive construction to some extent.

\section{References}

[1] Biber, D. (2000) Corpus Linguistics. Beijing: Foreign Language Teaching and Research Press.

[2] Biber, D. (1994) Corpus-based Approaches to Issues in Applied Linguistics. Applied linguistics: 15.

[3] Brown, H. D. (2006) Principles of Language Learning and Teaching. Beijing: Foreign Language Teaching Research Press. 
[4] Corder, S. P. (1974). 'the study of error is part of the investigation of the process of language learning. Error Analysis. Oxford: Oxford University Press: 125.

[5] Corder, S. P. (1967). The significance of learners' errors. International Review of Applied Linguistics. 5: 160-170.

[6] Ellis, R (1996) Understanding Second Language Acquisition. Shanghai: Shanghai Foreign Language Education Press.

[7] Ellis, R. (1999) The study of Second Language Acquisition. Shanghai: Shanghai Foreign Language Education Press.

[8] H. D. Brown. (2006) Principles of Language Learning and Teaching. Beijing: Foreign Language Teaching and Research Press.

[9] James, C. (2001) Errors in Language Learning and Use: Exploring Error Analysis. Beijing: Foreign Language Teaching and Research Press.

[10] Leech, G. (1984) Communicative Grammar of English. London: Longman.

[11] Quirk, R, S. Greenbaum, G. Leech and J. Svartvik. (1985) $A$ Comprehensive Grammar of the English Language. London: Longman.
[12] Richards J. C. (2000) Longman Dictionary of Language Teaching and Applied Linguistics. Beijing: Foreign Language Teaching and Research Press.

[13] Ke Ping, Comparative Linguistics, Nanjing: Nanjing Normal University Press, 1999.

[14] Lian Shuneng, Comparative Study between English and Chinese, Beijing: Higher Education Press, 1993.

[15] Li Rui, The phenomenon of Under-passivization in the language of Chinese College Students - A CLEC-Based Study, Gansu Higher Normal University Journal, 2007.

[16] Xu Yulong, An Introduction to Contrastive Linguistics, Shanghai: Shanghai Foreign Language Education Press, 2005.

[17] Xiong Xueliang, Wang Zhijun, A Cognitive Comparative Study of Passive Sentences between English and Chinese, Foreign Language Research, 2001.

[18] Zhuang Hongling, A Corpus-based Study of Chinese Learners' English Passive Voice Acquisition, Huazhong University of Science and Technology, 2005. 